\title{
Incorporation of Silicon Fume and Fly Ash as Partial Replacement of Portland Cement in Reinforced Concrete: Electrochemical study on corrosion behavior of 316LN stainless steel rebar
}

\author{
Caihong Zhang ${ }^{1, *}$, Fangfang Zhang $^{2}$ \\ ${ }^{1}$ Shaanxi Key Laboratory of Safety and Durability of Concrete Structures, Xijing University, Xian \\ 710123, China \\ ${ }^{2}$ Henan University of Science and Technology, Luoyang 471003, China \\ *E-mail: zchxjxy926@163.com
}

doi: $10.20964 / 2020.05 .77$

Received: 16 Janaury 2020 / Accepted: 3 March 2020 / Published: 10 April 2020

\begin{abstract}
In this work, corrosion behavior of 316LN stainless steel reinforced concrete incorporated by silicon fume (SF) and fly ash (FA) as partial replacement of Portland cement were investigated. Electrochemical impedance spectroscopy (EIS), polarization resistance measurement and open-circuit potential monitoring were used to study the corrosion behavior of stainless steel rebar. The $316 \mathrm{LN}$ stainless steel reinforced concrete samples were exposed to $3.5 \mathrm{wt} \% \mathrm{NaCl}$ solution as a marine environment. The electrochemical results showed that the steel reinforced concrete incorporated by SF and FA indicated the best corrosion behavior. The potential corrosion values were mainly related to region of $10 \%$ corrosion probability. The corrosion current density results indicated passivity state for concrete sample containing both FA and SF after 220 days of exposure time, and low corrosion probability during the experiment period. The EIS results showed that the value of double-layer capacitance decreased for the sample containing both FA and SF, indicating the passive film thickness increased and the resulting protective capacity enhanced. These results indicated that partial replacement of FA and SF simultaneously in Portland cement led to a reduced corrosion rate and enhanced corrosion resistance of steel rebar due to the reduction of water and chloride ion permeability.
\end{abstract}

Keywords: Corrosion resistance; Portland cement; Silicon fume; Fly ash; Electrochemical impedance spectroscopy; Polarization resistance

FULL TEXT 
(C) 2020 The Authors. Published by ESG (www.electrochemsci.org). This article is an open access article distributed under the terms and conditions of the Creative Commons Attribution license (http://creativecommons.org/licenses/by/4.0/). 